\title{
Saturated fatty acids activate microglia via Toll-like receptor 4/NF-кB signalling
}

\author{
Zhen Wang ${ }^{1}$, Dexiang Liu ${ }^{1}$, Fuwu Wang ${ }^{1}$, Shangming Liu ${ }^{1}$, Shidou Zhao ${ }^{1}$, Eng-Ang Ling $^{2}$ \\ and Aijun $\mathrm{HaO}^{1 *}$ \\ ${ }^{1}$ Shandong Provincial Key Laboratory of Mental Disorders, Department of Histology and Embryology, Shandong University \\ School of Medicine, 44\#, Wenhua Xi Road, Jinan, Shandong 250012, People's Repubic of China \\ ${ }^{2}$ Department of Anatomy, Yong Loo Lin School of Medicine, National University of Singapore, 4 Medical Drive, MD10, \\ Singapore 117597, Singapore
}

(Received 13 January 2011 - Revised 24 March 2011 - Accepted 30 March 2011 - First published online 29 June 2011)

\section{Abstract}

Diets rich in SFA have been implicated in Alzheimer's disease (AD). There is strong evidence to suggest that microglial activation augments the progression of AD. However, it remains uncertain whether SFA can initiate microglial activation and whether this response can cause neuronal death. Using the BV-2 microglial cell line and primary microglial culture, we showed that palmitic acid (PA) and stearic acid (SA) could activate microglia, as assessed by reactive morphological changes and significantly increased secretion of pro-inflammatory cytokines, NO and reactive oxygen species, which trigger primary neuronal death. In addition, the mRNA level of these pro-inflammatory mediators determined by RT-PCR was also increased by PA and SA. We further investigated the intracellular signalling mechanism underlying the release of pro-inflammatory mediators from PA-activated microglial cells. The present results showed that PA activated the phosphorylation and nuclear translocation of the p65 subunit of NF- $\kappa$ B. Furthermore, pyrrolidine dithiocarbamate, a NF- $\mathrm{B}$ inhibitor, attenuated the production of pro-inflammatory mediators except for IL-6 in PA-stimulated microglia. Administration of anti-Toll-like receptor (TLR)4-neutralising antibody repressed PA-induced NF- $\mathrm{BB}$ activation and pro-inflammatory mediator production. In conclusion, the present in vitro study demonstrates that SFA could activate microglia and stimulate the TLR4/NF-кB pathway to trigger the production of pro-inflammatory mediators, which may contribute to neuronal death.

\section{Key words: Microglia: SFA: NF-kB: Toll-like receptor 4}

Epidemiological data suggest that a diet rich in SFA is considered an increased risk factor for the development of Alzheimer's disease (AD). For example, in a 21-year follow-up study, it was found that abundant SFA intake from milk products and spreads at midlife was associated with poorer global cognitive function and prospective memory ${ }^{(1)}$. Other studies have demonstrated that a greater intake of saturated fat increased the risk for impaired cognitive function in middle-aged or aged populations ${ }^{(2-4)}$. This notion has been supported by animal studies. In this connection, it has been reported that rodents fed high levels of SFA also show impaired learning and memory performance and develop AD-like pathophysiological changes in their brains ${ }^{(5,6)}$. Fatty acids are free to cross the blood-brain barrier ${ }^{(7)}$. Therefore, brain fatty acid homeostasis may be dependent on their levels in the periphery. It is therefore conceivable that diets rich in SFA may increase brain uptake of intact NEFA from the plasma through the bloodbrain barrier ${ }^{(8)}$. In addition, the fatty acid profile of neurofibrillary tangles in the AD brain is rich in palmitic acid (PA) and stearic acid $(\mathrm{SA})^{(9)}$, and the white matter in the AD brain is characterised by high total fatty acid contents ${ }^{(10)}$.

PA and SA were reported to increase hyperphosphorylation of tau, and up-regulate $\beta$-secretase, the rate-limiting enzyme in the production of amyloid $\beta$ peptides in primary rat cortical neurons ${ }^{(11,12)}$. These actions were mediated by the above-mentioned two SFA on astrocytes, possibly through enhanced astrocytic synthesis of ceramide ${ }^{(13)}$. Several fatty acids have been reported to stimulate the aggregation of tau protein and amyloid $\beta$ in vitro ${ }^{(14)}$. Despite the accumulating data, the basic mechanism behind the causal relationship

Abbreviations: Ab, antibody; AD, Alzheimer's disease; BSA, bovine serum albumin; CNS, central nervous system; DHE, dihydroethidium; DMEM, Dulbecco's modified Eagle's medium; H $\mathrm{H}_{2}$ DCFDA, 2' $7^{\prime}$-dichlorodihydrofluorescein diacetate; iNOS, inducible NO synthase; LPS, lipopolysaccharide; MTT, 3-[4, 5dimethylthiazol-2-yl]-2, 5-diphenyltetrazolium bromide; PA, palmitic acid; PDTC, pyrrolidine dithiocarbamate; ROS, reactive oxygen species; SA, stearic acid; TLR, Toll-like receptor.

*Corresponding author: Dr Aijun Hao, email aijunhao@sdu.edu.cn 
between SFA and the pathogenesis of AD has not been well established.

It is well documented that microglia, the resident macrophages in the brain, play a central role in mediating chronic inflammatory conditions in $\mathrm{AD}^{(15)}$. In the ramified state, microglia actively survey the microenvironment and ensure normal central nervous system (CNS) activity by secreting neurotrophic factors such as neuronal growth factor. They are activated in response to specific stimuli and produce a host of pro-inflammatory cytokines, chemokines and reactive oxygen species (ROS). Although microglial activation plays an important role in phagocytosis of dead cells in the CNS, microglia cause inflammatory responses leading to neuronal death and brain injury when they are over-activated and dysregulated $^{(16)}$. Therefore, identification of the regulators involved in the initiation and maintenance of microglial activation may lead to a better understanding of inflammatory processes leading to AD. However, as far as can be ascertained, there is a total lack of information relating to the modulation of microglial activation by SFA. We report here that SFA could activate microglia to a pro-inflammatory state as evidenced by reactive morphological changes and significantly increased secretion of pro-inflammatory cytokines including TNF- $\alpha$, IL- $1 \beta$ and IL- 6 , as well as NO and ROS via Toll-like receptor (TLR) $4 / \mathrm{NF}-\kappa \mathrm{B}$ signalling in the microglial cell line, BV-2 cells, and primary cultures of mouse microglia.

\section{Materials and methods}

\section{Animals}

$\mathrm{BALB} / \mathrm{c}$ mice were used. All animals were obtained from the Laboratory Animal Centre, Shandong University. All animals were kept under controlled $12 \mathrm{~h}$ light $-12 \mathrm{~h}$ dark conditions, temperature $\left(23^{\circ} \mathrm{C}\right)$ and humidity $(60 \%)$. In the handling and care of all animals, the International Guiding Principles for Animal Research, as stipulated by the WHO (1985) and as adopted by the Laboratory Animal Centre, Shandong University, were followed. During the study, the number of animals used and their suffering were minimised.

\section{Microglial cell culture}

BV-2 cells were maintained in Dulbecco's modified Eagle's medium (DMEM; Hyclone Co., Logan, UT, USA) with $10 \%$ fetal bovine serum (Hyclone Co.), 2 mm-L-glutamine, penicillin $(100 \mathrm{U} / \mathrm{ml})$ and streptomycin $(100 \mu \mathrm{g} / \mathrm{ml})$ (Sigma-Aldrich, St Louis, MO, USA) in a $5 \% \mathrm{CO}_{2}$ incubator. For all experiments, BV-2 cells were used at 75 to $80 \%$ confluency. Before the experiment, plated cells were incubated with serum-free DMEM for $1 \mathrm{~h}$. After this, the medium was replaced with serum-free DMEM containing either PA (16:0; SFA) (Sigma-Aldrich), SA (18:0; SFA) (Sigma-Aldrich), lipopolysaccharide (LPS; SigmaAldrich), pyrrolidine dithiocarbamate (PDTC; Sigma-Aldrich) or anti-TLR4-neutralising antibody (anti-TLR4 Ab; eBioscience, Inc., San Diego, CA, USA) for the indicated times.

Primary microglia were prepared from the whole brains of mice, aged $1-2 \mathrm{~d}$, as described previously ${ }^{(17)}$. Briefly, glial cells were cultured for $14 \mathrm{~d}$ in DMEM/F12 (Hyclone Co.) supplemented with $10 \%$ fetal bovine serum (Hyclone Co.). Then the mixed glial cultures were shaken on an orbital shaker at $250 \mathrm{rpm}$ for $2 \mathrm{~h}$ to dislodge microglial cells. The separate microglial cells were plated into twenty-four-well plates at a density of $2 \times 10^{5}$ cells/well. The purity of the microglia cultures was assessed using CD11b Ab and more than $97 \%$ of cells were stained positively. Cells were cultured for $7 \mathrm{~d}$ before treatment.

\section{Preparation of fatty acid-albumin complexes}

PA or SA was solubilised in ethanol at $70^{\circ} \mathrm{C}$. Then PA or SA was combined with fatty acid-free and low-endotoxin bovine serum albumin (BSA) at a molar ratio of 10:1 (fatty acid:albumin) in serum-free medium at $50^{\circ} \mathrm{C}$ for $6 \mathrm{~h}$ for a final PA or SA concentration of $25-200 \mu \mathrm{M}$ as described previously ${ }^{(18)}$. The fatty acid-albumin complex solution was freshly prepared before each experiment. The final concentration of ethanol was $<0.5 \%$. In most of the experiments, BV-2 cells or primary microglial cells were treated with individual SFA at $25-200 \mu \mathrm{M}$ concentration, while the controls received BSA and vehicle only.

To evaluate the possible contamination of PA or SA with LPS, the endotoxin content was determined by the chromogenic Limulus amebocyte lysate test, following the manufacturer's instructions (Cambrex Bio Science, Walkersville, $\mathrm{MD}$, USA). The endotoxin content in the $100 \mu \mathrm{M}-\mathrm{PA}$ and $100 \mu \mathrm{m}-\mathrm{SA}$ solution was $\leq 3.45 \times 10^{-3} \mathrm{pg} / \mathrm{ml}$, which is far below the concentration required to induce microglial activation under our assay conditions.

\section{Conditioned medium}

To assess bystander neuronal death by factors released by microglial cells following PA treatment, BV-2 cells were seeded in $60 \mathrm{~mm}$ culture plates at a density of $3 \times 10^{5}$ cells/ plate. After the cells became confluent, they were incubated with serum-free DMEM for $1 \mathrm{~h}$. After this, the medium was replaced by serum-free DMEM containing appropriate fatty acid-albumin complexes for $12 \mathrm{~h}$. Controls received BSA and vehicle only. After $12 \mathrm{~h}$, the medium was changed with fresh serum-free DMEM for $12 \mathrm{~h}$, and then the supernatant fractions were collected, filtered and added onto primary neurons cultured in poly-D-lysine-coated twelve-well plates.

\section{Neuronal culture and apoptosis analysis}

Primary cultures of mouse cortical neurons were prepared as previously described ${ }^{(19)}$. Briefly, cortical neurons were harvested from mice, aged 1-2 d, using the serum-free Neurobasal medium with B27 supplement system (Invitrogen Corp., Carlsbad, CA, USA). Cortical cells were plated at a density of $1.5 \times 10^{6}$ cells per well in poly-D-lysine-coated twelve-well plates and allowed to differentiate for $7 \mathrm{~d}$. At day 7 , the mouse neuronal medium was removed and replaced by a conditioned medium from microglial cells. Neurons were incubated with microglia-conditioned medium for $2 \mathrm{~d}$, and 
then analysed by Hoechst 33342 nuclei staining for the detection of morphological features of apoptotic cell death.

Hoechst was added to the culture medium at a final concentration of $10 \mu \mathrm{g} / \mathrm{ml}$, which was then incubated in the dark at $100 \%$ humidity for $10 \mathrm{~min}$ at $37^{\circ} \mathrm{C}$. The cells were then examined under a fluorescence microscope. Undamaged cell nuclei were large and diffusely stained whereas apoptotic nuclei showed chromatin that was condensed and fragmented.

\section{ELISA}

BV-2 cells $\left(3 \times 10^{5}\right.$ cells per well in a twelve-well plate $)$ were pretreated with different concentrations of PA $(0,25,50$ or $100 \mu \mathrm{M})$, LPS or inhibitors at the indicated times. The supernatant fraction of the culture medium from the various treatments was then collected. The levels of cytokines, TNF$\alpha$, IL- $1 \beta$ and IL- 6 in the culture medium were measured using commercially available ELISA kits (R\&D Systems Inc., Minneapolis, MN, USA) according to the manufacturer's instructions. Briefly, serial dilutions of protein standards and samples were added to ninety-six-well ELISA plates, followed by biotinylated anti-TNF- $\alpha$, IL- $1 \beta$ or IL- $6 \mathrm{Ab}$. After rinsing with wash buffer, the prepared solution of avidin, horseradish peroxidase-conjugated complex was added followed by the addition of substrate solution. The reaction was terminated by the stopping solution. The optical density was detected at $450 \mathrm{~nm}$ in a microplate reader (Bio-Rad Laboratories, Hercules, CA, USA). Each sample concentration was calculated from the linear equation derived from the standard curve of known concentrations of the cytokine.

\section{Assay of NO production}

BV-2 cells $\left(3 \times 10^{5}\right.$ cells per well in a twelve-well plate), were pretreated with different concentrations of PA $(0,25,50$ or $100 \mu \mathrm{M})$, LPS or inhibitors at the indicated times. The supernatant fraction of the culture medium from the various treatments was collected. NO production was assessed by measuring the accumulation of nitrite in the culture medium by the Griess reaction. The culture medium was mixed with an equal volume of Griess reagent $(0 \cdot 1 \% N$-1-naphthylethylenediamine dihydrochloride and $1 \%$ sulfanilamide in $5 \%$ phosphoric acid; Sigma-Aldrich) in a ninety-six-well plate and incubated at room temperature for $10 \mathrm{~min}$. Absorbance was measured at $550 \mathrm{~nm}$ in a microplate reader (Bio-Rad Laboratories). Sodium nitrite, diluted in culture medium at concentrations ranging from 10 to $100 \mu \mathrm{m}$, was used to prepare a standard curve.

\section{Reactive oxygen species assay}

Intracellular ROS levels were measured by $2^{\prime}, 7^{\prime}$-dichlorodihydrofluorescein diacetate $\left(\mathrm{H}_{2}\right.$ DCFDA $)$ and dihydroethidium (DHE) assays. $\mathrm{H}_{2}$ DCFDA or DHE is a membrane-permeable dye that is oxidised by intracellular ROS to the fluorescent product DCF or ethidium, respectively. Briefly, BV-2 cells were stimulated with or without PA, or LPS for 12 or $24 \mathrm{~h}$, and the culture medium was first removed. The cells were washed three times with PBS, and were incubated with either $10 \mu \mathrm{M}$ $\mathrm{H}_{2}$ DCFDA or $2 \mu \mathrm{M}$-DHE (Molecular Probes, Eugene, OR, USA) for $20 \mathrm{~min}$ at $37^{\circ} \mathrm{C}$. The cells were then washed three times with PBS and examined with a Nikon TE2000U microscope (Nikon, Tokyo, Japan). The fluorescence was measured at $485 \mathrm{~nm}$ for excitation and $530 \mathrm{~nm}$ for emission with a fluorescence plate reader (Fluroskan Ascent II; Labsystems, Helsinki, Finland). The increased value compared with control was considered as the increase of intracellular ROS.

\section{Cell viability assay}

Cell viability was determined using the 3-[4, 5-dimethylthiazol2-yl]-2, 5-diphenyltetrazolium bromide (MTT) assay. BV-2 cells were plated into ninety-six-well culture plates at a density of $1 \times 10^{4}$ cells/well with $200 \mu \mathrm{l}$ culture medium per well in triplicate. When reaching $75 \%$ confluency, the cells were incubated in the absence or presence of PA (25, 50, 100, $200 \mu \mathrm{M})$, respectively, for $48 \mathrm{~h}$. Then, $20 \mu \mathrm{l}$ MTT solution $(5 \mathrm{mg} / \mathrm{ml}$; Sigma-Aldrich) were added to each well and incubated at $37^{\circ} \mathrm{C}$ for $4 \mathrm{~h}$. The culture medium was aspirated and followed by the addition of $200 \mu$ l dimethyl sulfoxide. The absorbance value was measured in a microplate reader (Bio-Rad Laboratories) at $490 \mathrm{~nm}$. Values were expressed as a percentage relative to those obtained in controls.

\section{Immunocytochemistry}

Microglial cells were seeded onto glass coverslips. Following treatment with or without PA, LPS or inhibitors at the indicated times, cells were fixed in $4 \%$ paraformaldehyde for $10 \mathrm{~min}$, and blocked with $10 \%$ goat serum in PBS. Slides were incubated overnight in a humid chamber at $4^{\circ} \mathrm{C}$ with the primary $\mathrm{Ab}$ (mouse monoclonal anti-CD11b Ab (1:100 dilution); rabbit polyclonal anti-inducible $\mathrm{NO}$ synthase (iNOS) Ab (1:100 dilution); rabbit monoclonal anti-NF-кB p65 Ab (1:100 dilution); all Cell Signaling Technology, Beverly, MA, USA). After primary $\mathrm{Ab}$ incubation, samples were washed again and incubated in the appropriate fluorescent-conjugated secondary $\mathrm{Ab}$ (goat anti-mouse/rabbit $\operatorname{IgG}$ (1:100 dilution); Sigma-Aldrich) for $1 \mathrm{~h}$. The cells were counterstained by 4',6-diamidino-2-phenylindole (DAPI). Images were captured with a Nikon TE2000U microscope.

\section{Reverse transcription-PCR}

Total RNA was extracted from induced cell cultures using the Trizol reagent (Gibco, Invitrogen Corp.) according to the manufacturer's instructions. RNA concentration was determined by a spectrophotometer (Bio-Rad Laboratories) at $260 \mathrm{~nm}$. Identical amounts of RNA $(1 \mu \mathrm{g})$ were reverse transcribed into cDNA by using a commercial RT-PCR kit (Fermentas, Vilnius, Lithuania) according to the manufacturer's instructions. cDNA was subsequently amplified by PCR with specific primers (Table 1). PCR amplification of the resulting cDNA template was conducted by using the following conditions for thirty-two (TNF- $\alpha$, IL-6, iNOS and $\beta$-actin) and thirty-five (IL-1 $\beta$ ) cycles; denaturation at $94^{\circ} \mathrm{C}$ for $30 \mathrm{~s}$, annealing at 
Table 1. PCR primers used in the present study

\begin{tabular}{|c|c|c|}
\hline Gene & Forward & Reverse \\
\hline TNF- $\alpha$ & 5'-CGTCAGCCGATTTGCTATCT-3' & 5'-CGGACTCCGCAAAGTCTAAG-3' \\
\hline IL-1 $\beta$ & 5'-AAGATGAAGGGCTGCTTCCAA ACC-3' & 5'-ATACTGCCTGCCTGAAGCTCTTGT-3' \\
\hline IL-6 & 5'-CCACTTCACAAGTCGGAGGCTT-3' & 5'-CCAGCTTATCTGTTAGGAGA-3' \\
\hline iNOS & 5'-ССТССТССАСССТАССАAGT-3' & 5'-CACCCAAAGTGCTTCAGTCA-3' \\
\hline$\beta$-Actin & $5^{\prime}$-GTGGGGCGCCCCAGGCACCA-3' & 5'-CTTCCTTAATGTCACGCACGATTTC-3' \\
\hline
\end{tabular}

iNOS, inducible NO synthase.

$60^{\circ} \mathrm{C}$ for $45 \mathrm{~s}$, and extension at $72^{\circ} \mathrm{C}$ for $30 \mathrm{~s}$. PCR products separated on a $1.2 \%$ agarose-Tris-acetate-EDTA (TAE) gel were visualised by staining with ethidium bromide. The densitometric analysis of the data was normalised to $\beta$-actin. The intensity of bands was determined using the Image-Pro Plus 6.0 software (Media Cybernetics, Inc., Bethesda, MD, USA).

\section{Western blot analysis}

Cell-associated proteins were washed with cold PBS and lysed in ice-cold radioimmunoprecipitation assay (RIPA) buffer containing protein inhibitors. Cell lysates were incubated at $4^{\circ} \mathrm{C}$ for $20 \mathrm{~min}$. The sample was centrifuged at $12000 \mathrm{rpm}$ for $10 \mathrm{~min}$ at $4^{\circ} \mathrm{C}$, the supernatant fraction was then collected and protein concentration was assayed colorimetrically. A quantity of $30 \mu \mathrm{g}$ total proteins was loaded onto a $4-20 \%$ gradient polyacrylamide gel, electrophoretically transferred to a polyvinylidene difluoride membrane and probed with primary antibodies (rabbit polyclonal anti-phospho-NF-кB p65 (S536) $\mathrm{Ab}$ (1:500 dilution), Bioworld Technology, Inc., Minneapolis, MN, USA; rabbit monoclonal anti-NF-кB p65 Ab (1:1000 dilution), Cell Signaling Technology; rabbit polyclonal antiiNOS Ab (1:1000 dilution), Cell Signaling Technology). Mouse monoclonal anti- $\beta$-actin (1:2000 dilution; SigmaAldrich) was used as an internal control. Secondary antibodies were horseradish peroxidase conjugated to goat/mouse antirabbit IgG (1:5000 dilution; Sigma-Aldrich). The membranes were developed using an enhanced chemiluminescence detection system (Pierce, Rockford, IL, USA).

\section{Transient transfection and luciferase reporter gene assay}

The NF- $\mathrm{BB}$ reporter plasmid contained three copies of the NF- $\mathrm{B}$-binding sequence fused to the firefly luciferase gene (Clontech Laboratories, Inc., Mountain View, CA, USA). The cells were cultured in a twenty-four-well plate until they reached $75-80 \%$ confluency. Transfection of the NF-кB reporter gene into the cells was performed using Lipofectamine 2000 (Invitrogen Corp.) according to the manufacturer's instructions. Cells were transfected with $0.8 \mu \mathrm{g} \mathrm{NF- \kappa B}$ reporter plasmid, $0.04 \mu \mathrm{g}$ pRL-TK vector (Promega Corp., Madison, WI, USA) mixed with Lipofectamine 2000. After $48 \mathrm{~h}$, cells were harvested and a luciferase assay was performed. To determine SFA-induced NF- $\kappa$ B activity, cells were incubated with or without PA or LPS for $24 \mathrm{~h}$ before harvesting cells for the luciferase assay. Luciferase assays were performed using the DualLuciferase reporter assay system (Promega Corp.) according to the manufacturer's instructions. Luciferase activity was measured using a Monolight 2010 luminometer (Analytical Luminescence Laboratory, San Diego, CA, USA). Renilla luciferase activity was used as an internal control. The relative luciferase activity was then calculated by normalising firefly luciferase activity to Renilla luciferase activity.

\section{Statistical analysis}

Quantitative data are presented as the mean values and standard deviations of at least three independent experiments. Statistical analysis of data was done by Student's $t$ test or by one-way ANOVA using Dunnett's test in multiple comparisons of means. Differences were considered statistically significant if the $P$ value was $<0 \cdot 05$.

\section{Results}

\section{Treatment with SFA led to activation of microglial cells}

In order to confirm that incubation with SFA would not induce microglia death, cell viability was assessed at $48 \mathrm{~h}$ after PA treatment by MTT. BV-2 cell viability following treatment with PA at $25 \mu \mathrm{M}(94.78$ (SD 4.34) \%), $50 \mu \mathrm{M}$ (101.09 (SD $14.61) \%$ ) and $100 \mu \mathrm{M}(89.49$ (SD 6.51) \%) was not significantly different from the control (100.08 (SD 5) \%). However, exposure of BV-2 cells to PA at $200 \mu \mathrm{M}$ resulted in significantly fewer viable cells (66.82 (SD 4.91) \%) as compared with cells in the control condition (Fig. 1(a)). In view of this and because $\mathrm{PA}$ is common in the diet and constitutes a large proportion of circulating NEFA, we used PA $(25,50$ and $100 \mu \mathrm{M})$ as a representative SFA in most of the subsequent experiments.

The MTT assay showed that PA did not have any cytotoxicity at the concentrations of 25,50 and $100 \mu \mathrm{M}$ for at least $48 \mathrm{~h}$ on primary microglia (Fig. 1(a)); it was clearly toxic to cells at the concentration of $200 \mu \mathrm{M}$.

It is interesting to note that primary microglia were activated following treatment with PA for 6 and $24 \mathrm{~h}$. This was manifested by light microscopic imaging which showed that after 6 and $24 \mathrm{~h}$ incubation with PA $(100 \mu \mathrm{M})$, cells assumed a round outline or appeared amoeboid in form compared with the control cells treated with BSA and vehicle which were mostly ramified with numerous, long extending processes; very few amoeboid cells were observed in the control condition (Fig. 1(b)). Moreover, BV-2 cells treated with LPS $(500 \mathrm{ng} / \mathrm{ml})$ for 6 and $24 \mathrm{~h}$ also showed an activated morphology (data not shown).

Microglial activation is associated with a marked increase in CD11b expression ${ }^{(20)}$. At $24 \mathrm{~h}$ after treatment with PA 
$(100 \mu \mathrm{M})$, or LPS $(500 \mathrm{ng} / \mathrm{ml})$, the present results showed that there was dramatically increased CD11b expression in primary microglial cells (Fig. 1(c)).

\section{SFA induced expression and secretion of pro-inflammatory cytokines}

RT-PCR analysis showed that in BV-2 cells exposed to different concentrations of PA $(25,50$ and $100 \mu \mathrm{M})$ or LPS (500 ng/ $\mathrm{ml}$ ) for $4 \mathrm{~h}$, the levels of TNF- $\alpha$, IL- $1 \beta$ and IL- 6 mRNA expression were significantly increased compared with the control (Fig. 2(a) and (b)). By ELISA, we then determined the production of TNF- $\alpha$, IL- $1 \beta$ and IL- 6 in the medium of BV-2 cells treated with PA at different concentrations (25, 50 and $100 \mu \mathrm{M}$ ) for 12,24 and $48 \mathrm{~h}$. As a positive control, BV-2

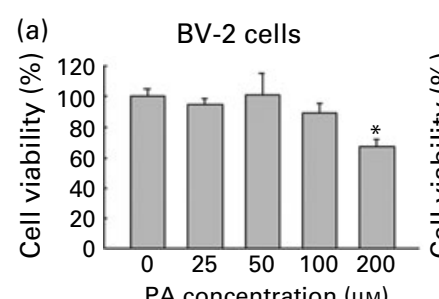

(b)

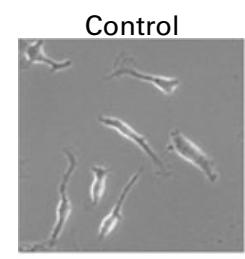

(c)
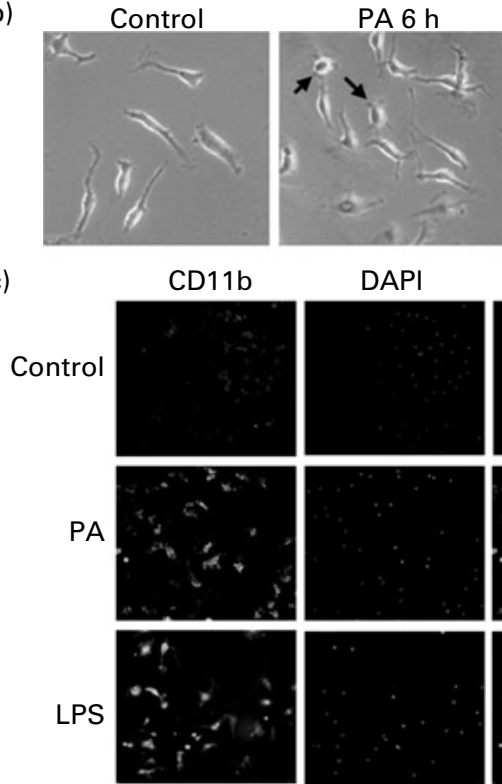

DAPI
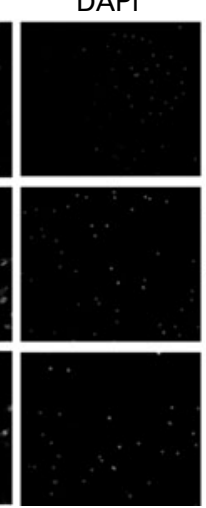

Fig. 1. Effects of SFA treatment on microglia. (a) BV-2 cells and primary microglial cells maintained in serum-free medium were incubated in the absence or presence of indicated concentrations of palmitic acid (PA; 25$200 \mu \mathrm{M}$ ) for $48 \mathrm{~h}$ and cell viability was performed by the 3-[4, 5-dimethylthiazol-2-yl]-2, 5-diphenyltetrazolium bromide (MTT) assay. Three independent experiments were conducted. Values are the means of three independent experiments, with standard deviations represented by vertical bars. * Mean value was significantly different from that of the control $(P<0.05)$. (b) Primary microglial cells were incubated in the absence or presence of PA $(100 \mu \mathrm{M})$ for 6 and $24 \mathrm{~h}$, then microscopic images were taken. Scale bar $=50 \mu \mathrm{m}$. Images are representative of triplicate sets. $\rightarrow$, Primary microglial cells with a round outline or amoeboid in form. (c) Primary microglial cells were incubated in the absence or presence of PA $(100 \mu \mathrm{M})$ or lipopolysaccharide (LPS; $500 \mathrm{ng} / \mathrm{ml}$ ) for $24 \mathrm{~h}$, then stained with anti-CD11b, and counterstained with 4',6-diamidino-2-phenylindole (DAPI). Scale bar $=100 \mu \mathrm{m}$. Images are representative of triplicate sets. cells were stimulated with LPS $(500 \mathrm{ng} / \mathrm{ml})$ for $24 \mathrm{~h}$. As shown in Fig. 2(c), both LPS and PA, at either low or high concentrations, stimulated microglia to produce increased amounts of cytokines. In addition, PA stimulated the release of TNF- $\alpha$, IL- $1 \beta$ and IL- 6 in BV-2 cells from $12 \mathrm{~h}$ onward at all the concentrations $(25,50$ and $100 \mu \mathrm{M})$; the maximum production was observed at $24 \mathrm{~h}$. Remarkably, IL-1 $\beta$ secretion of the PA-treated microglia (409.47 (sD 54.54) pg/ml) was higher than that in LPS-treated cells (306.93 (sD 45.10) pg/ml) (Fig. 2(c)) at $24 \mathrm{~h}$. Nonetheless, the levels of TNF- $\alpha$ and IL- 6 were about 1- to 2-fold higher in LPS (TNF- $\alpha, 451 \cdot 14$ (SD 40.95) $\mathrm{pg} / \mathrm{ml}$; IL-6, 209.88 (SD 22.60) $\mathrm{pg} / \mathrm{ml}$ ) than those in the PA-treated microglia (TNF- $\alpha, 344.06$ (SD 18.38) $\mathrm{pg} / \mathrm{ml}$; IL-6, 65.19 (sD 8.49) $\mathrm{pg} / \mathrm{ml})$ at $24 \mathrm{~h}$.

\section{SFA caused increased NO release and intracellular inducible NO synthase levels}

We first tested the effect of PA on NO release by measuring nitrite quantities in the supernatant fractions of BV-2 cell culture. It was found that upon treatment with different concentrations of PA $(25,50$ and $100 \mu \mathrm{M})$ for 12,24 and $48 \mathrm{~h}$ or LPS $(500 \mathrm{ng} / \mathrm{ml})$ for $24 \mathrm{~h}$, NO release was significantly increased from the cells in all three treatment groups in a dose-dependent and time-dependent manner compared with the control (Fig. 3(a)). The cells exposed to different concentrations of PA $(25,50$ and $100 \mu \mathrm{m})$ for $4 \mathrm{~h}$ also exhibited an increase in iNOS mRNA expression in a dose-dependent manner (Fig. 3(b) and (c)).

In conjunction with nitrite quantification, iNOS expression responsible for NO production was evaluated by Western blot and immunocytochemistry. Western blot results showed that PA dose-dependently increased iNOS expression in BV-2 cells (Fig. 3(c)). Moreover, in the PA (100 $\mu \mathrm{M})$-treated group, iNOS expression was higher than that in LPS-treated cells. By immunofluorescence, iNOS expression was induced after $6 \mathrm{~h}$ of treatment with PA $(100 \mu \mathrm{M})$ in primary microglia cells; at $24 \mathrm{~h}$ after treatment, the expression was visibly more intense (Fig. 3(d)). In order to investigate whether the above effects are PA specific, we then tested another SFA - SA, which is present in the serum, accounting for close to $13 \%$ of the total fatty acids. We found that treatment with $100 \mu \mathrm{m}-\mathrm{SA}$ (a non-toxic concentration) for $4 \mathrm{~h}$ also induced a marked morphological change (data not shown) and increased expression of pro-inflammatory cytokine mRNA and iNOS mRNA in BV-2 cells (Fig. 3(e)). These results suggest that SFA play a rather general role in microglial activation.

\section{SFA caused elevation of reactive oxygen species production}

We next examined whether SFA treatment could affect intracellular ROS levels in BV-2 cells. The cells were treated with PA $(100 \mu \mathrm{M})$ for 12 and $24 \mathrm{~h}$, or LPS $(500 \mathrm{ng} / \mathrm{ml})$ for $24 \mathrm{~h}$, following the addition of the ROS fluorescent probes $\mathrm{H}_{2}$ DCFDA and DHE to detect $\mathrm{H}_{2} \mathrm{O}_{2}$ and superoxide $\left(\mathrm{O}_{2}{ }^{-}\right)$production, respectively (Fig. 4(a)). It was observed that both PA 
(a)

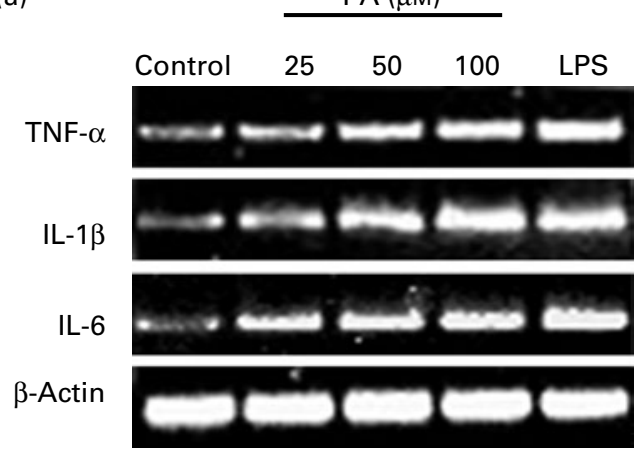

(b)

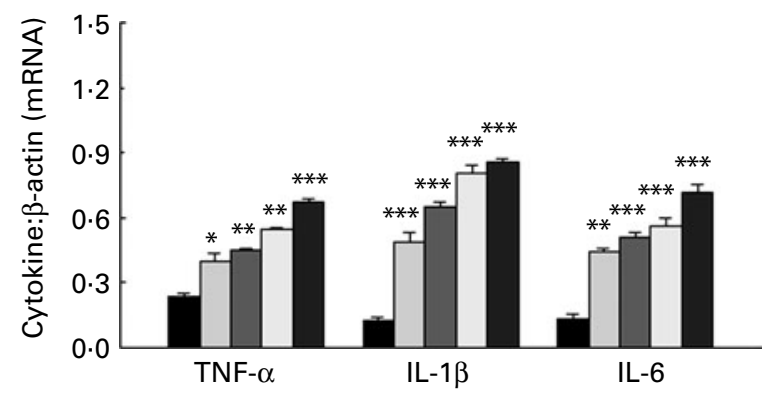

(c)
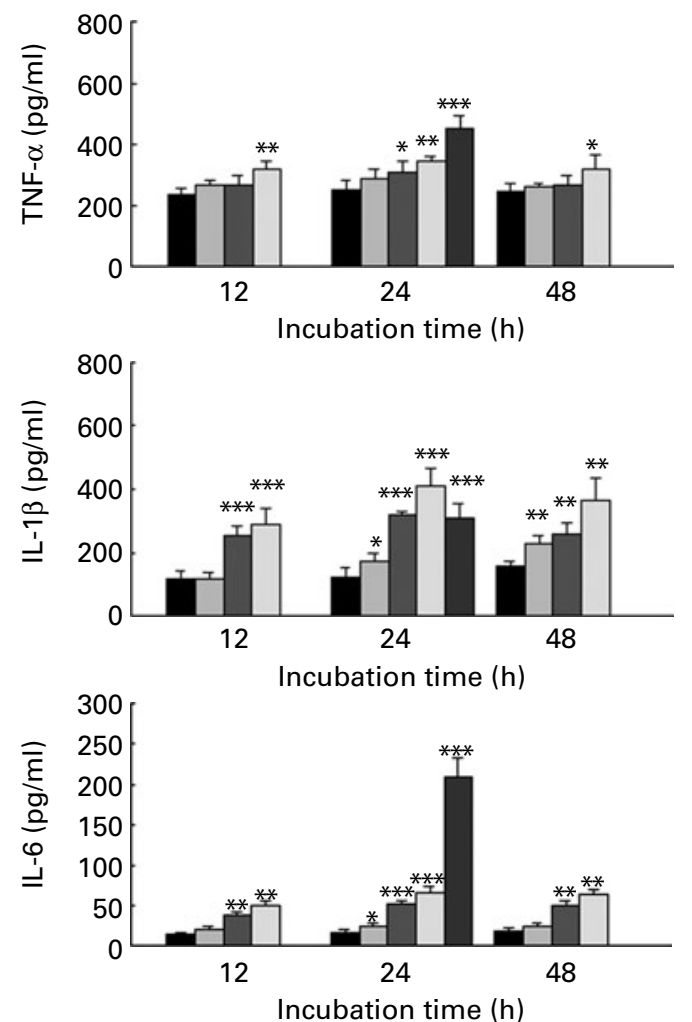

Fig. 2. SFA increase pro-inflammatory cytokine mRNA expression and secretion. (a) BV-2 cells cultured in triplicate were incubated in the absence or presence of palmitic acid (PA; 25-100 $\mu \mathrm{M}$ ) or lipopolysaccharide (LPS; $500 \mathrm{ng} / \mathrm{ml}$ ) for $4 \mathrm{~h}$. The relative expression levels of TNF- $\alpha$, IL-1 $\beta$ and IL- 6 genes were analysed by semi-quantitative RT-PCR. Each value was normalised to $\beta$-actin. (b) Quantification of mRNA levels of the various cytokines determined by Image-Pro Plus 6.0. (c) BV-2 cells cultured in triplicate were incubated in the absence or presence of PA $(25-100 \mu \mathrm{M})$ for 12,24 and $48 \mathrm{~h}$ or LPS $(500 \mathrm{ng} / \mathrm{ml})$ for $24 \mathrm{~h}$. The levels of

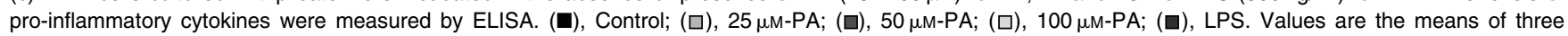
independent experiments, with standard deviations represented by vertical bars. Mean value was significantly different from that of the control: * $P<0.05$, ${ }^{\star *} P<0.01,{ }^{* \star *} P<0.001$.

and LPS markedly increased $\mathrm{H}_{2} \mathrm{O}_{2}$ and $\mathrm{O}_{2}{ }^{-}$production in $\mathrm{BV}-2$ cells compared with the control (Fig. 4(b)).

\section{Activation of microglia by palmitic acid treatment leads to bystander neuronal death}

Activated microglia are known to produce an array of cytokines and other inflammatory mediators that are in turn deleterious for surrounding neurons in the $\mathrm{CNS}^{(21)}$. BV-2 cells were incubated in the absence or presence of PA (25, 50 and $100 \mu \mathrm{M}$ ) for $12 \mathrm{~h}$ and the medium was changed with fresh serum-free DMEM. After $12 \mathrm{~h}$, supernatant fractions were collected and filtered. To check whether PA-induced microglia activation causes bystander neuronal death, we treated primary neurons with the medium mentioned above. The control comprised culture supernatant fractions from BSA- and vehicle-treated BV-2 cells. Primary cortical neurons were incubated with microglia-conditioned medium for $2 \mathrm{~d}$ and then neuronal apoptosis was measured by morphological analysis. The results in Fig. 5 demonstrated a significant induction of apoptosis in the neurons. These results indicate that microglia produced inflammatory mediators in response to PA and that the mediators accumulated in the medium were capable of inducing neuronal death.

\section{SFA-activated NF- $\kappa B$ signalling}

$\mathrm{NF}-\kappa \mathrm{B}$ is an essential transcription factor for the expression of cytokine and iNOS expression in microglia ${ }^{(22)}$. We therefore investigated the potential nuclear translocation of NF- $\kappa \mathrm{B}$ following the stimulation of microglia with PA. For these experiments, BV-2 cells were treated with or without PA $(100 \mu \mathrm{M})$ or LPS $(500 \mathrm{ng} / \mathrm{ml})$ for $1 \mathrm{~h}$, and the p 65 subunit of NF- $\mathrm{KB}$ in the nuclear fraction was assessed by using immunofluorescence. It was observed that either PA or LPS was capable of activating $\mathrm{NF}-\kappa \mathrm{B}$, as demonstrated by the increased levels of the NF- $\mathrm{B}$ subunit, p65, in the nucleus, whereas p65 was localised primarily in the cytosol during the resting state (Fig. 6(a)).

It has been demonstrated that phosphorylation of serine residues 529 and 536 of the RelA/p65 subunit leads to a transactivation of NF- $\mathrm{KB}^{(23)}$. We next investigated whether PA regulates the phosphorylation of $\mathrm{p} 65$. The proteins harvested from the cells after $1 \mathrm{~h}$ treatment with or without PA (25, 50 and $100 \mu \mathrm{M}$ ) were processed for Western blot to detect intracellular levels of phospho-p65 (ser536). As shown in Fig. 6(b), phospho-p65 levels were significantly elevated in all three treatment groups

In order to observe the effect of PA on the transcriptional activity of NF-кB, cells were transfected with a plasmid construct containing $3 \times \mathrm{NF}-\mathrm{\kappa B}$ binding sites associated with the 


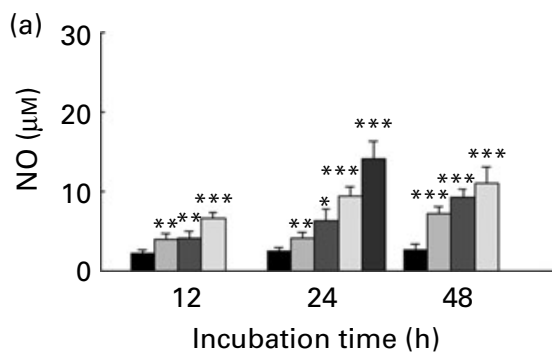

(b)

(d)
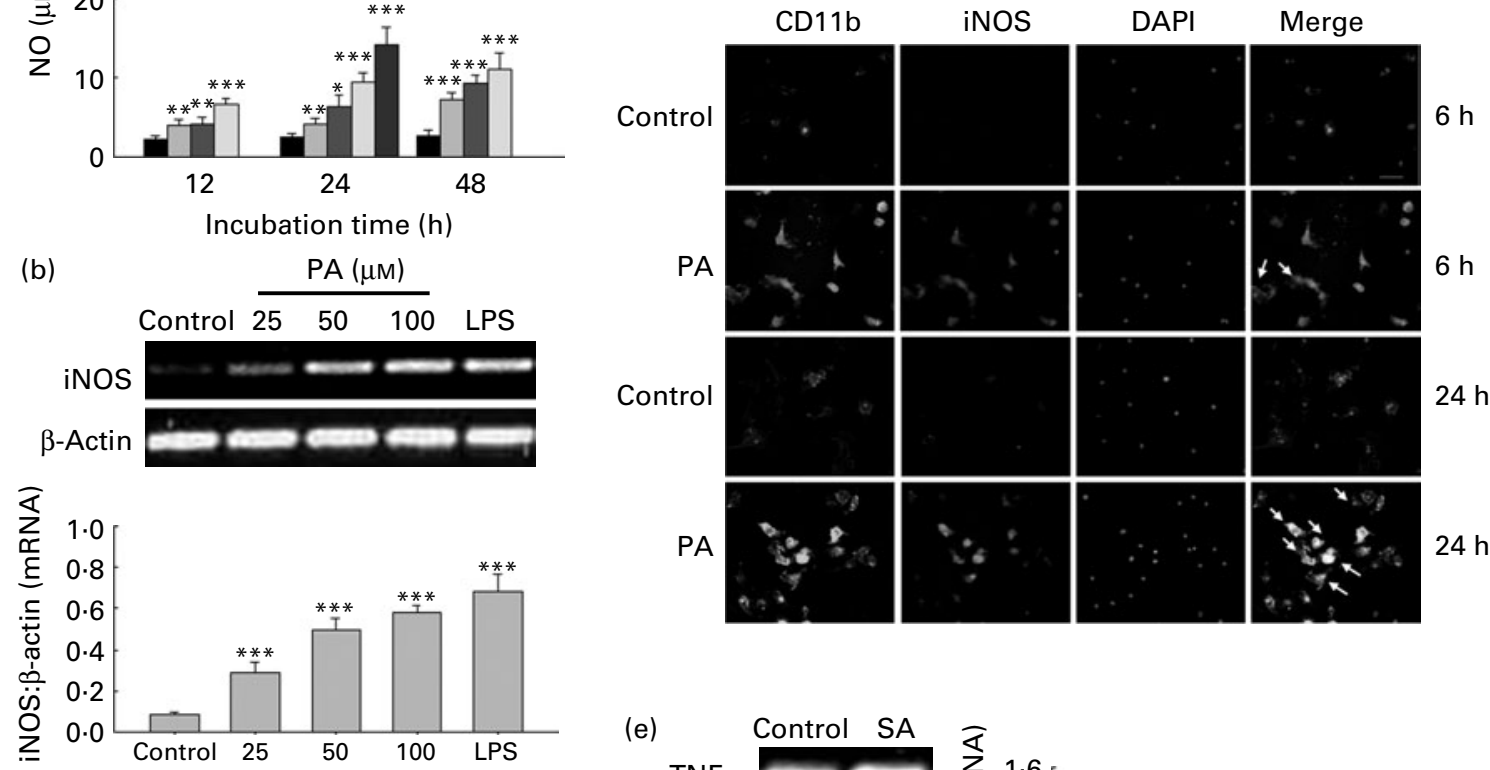

PA concentration $(\mu \mathrm{M})$

(c)
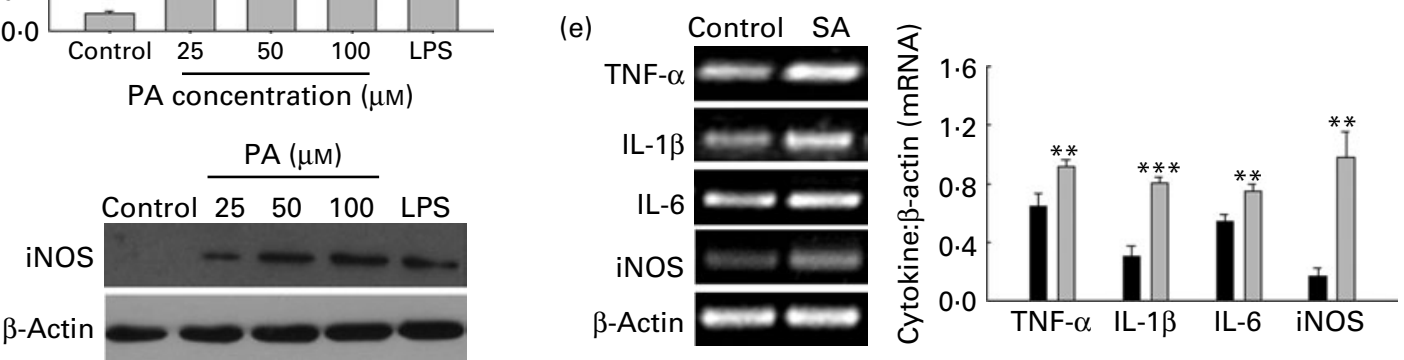

Fig. 3. SFA cause elevated NO release from BV-2 cells and increase inducible NO synthase (iNOS) expression. (a) NO was determined by Greiss reagent after BV-2 cells cultured in triplicate were incubated in the absence or presence of palmitic acid (PA; 25-100 $\mu \mathrm{M}$ ) for 12, 24 and $48 \mathrm{~h}$, or lipopolysaccharide (LPS;

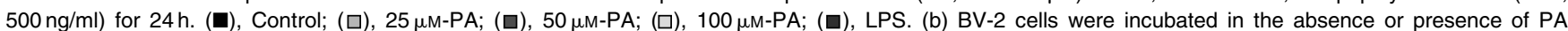
$(25-100 \mu \mathrm{M})$ or LPS $(500 \mathrm{ng} / \mathrm{ml})$ for $4 \mathrm{~h}$. The relative expression level of the iNOS gene was analysed by semi-quantitative RT-PCR. Each value was normalised to $\beta$-actin. Quantification of the mRNA levels of iNOS determined by Image-Pro Plus 6.0. (c) BV-2 cells were incubated in the absence or presence of PA $(25-100 \mu \mathrm{M})$ or LPS $(500 \mathrm{ng} / \mathrm{ml})$ for $24 \mathrm{~h}$ and $30 \mu \mathrm{g}$ of total protein were subjected to Western blot analysis. (d) Following treatment with or without PA (100 $\mu \mathrm{M}$ ) for $6 \mathrm{~h}$ and $24 \mathrm{~h}$, primary microglial cells were stained with anti-CD11b, anti-iNOS and counterstained with 4',6-diamidino-2-phenylindole (DAPI). Scale bar $=50 \mu \mathrm{m}$. (e) BV-2 cells were incubated in the absence $(\square)$ or presence $(\square)$ of stearic acid (SA; $100 \mu \mathrm{M})$ for $4 \mathrm{~h}$. The relative expression levels of TNF- $\alpha$, IL-1 13 , IL-6 and iNOS genes were analysed by semi-quantitative RT-PCR. Quantification of mRNA determined by Image-Pro Plus 6.0. Images are representative of triplicate sets. Values are the means of three independent experiments, with standard deviations represented by vertical bars. Mean value was significantly different from that of the control: ${ }^{* *} P<0.01,{ }^{* \star *} P<0.001$.

luciferase reporter plasmid and a control vector. It was observed that PA $(25,50$ and $100 \mu \mathrm{M})$ exposure induced NF$\kappa \mathrm{B}$-driven luciferase activity in a dose-dependent manner (Fig. 6(c)).

\section{NF- $\kappa B$ inhibitor suppressed SFA-induced pro-inflammatory cytokines and NO production}

The role of NF- $\mathrm{KB}$ in PA-induced pro-inflammatory cytokines and NO production was examined using the specific NF-кB pathway inhibitor PDTC. In BV-2 cells treated with PDTC (100 $\mu \mathrm{M}$, a non-toxic concentration), for $4 \mathrm{~h}$, PA-induced gene expression of iNOS and pro-inflammatory cytokines was significantly suppressed (Fig. 7(a) and (b)). In addition, PDTC reduced PA-induced NO, TNF- $\alpha$ and IL- $1 \beta$ secretion (Fig. 7(c)). However, PDTC did not exert a significant effect on PA-induced IL-6 production (Fig. 7(c)). Taken together with the result shown in Fig. 6, these findings indicate that
SFA are capable of inducing a rapid response of $\mathrm{NF}-\mathrm{\kappa B}$ in microglia, triggering the expression of cytokines (for example, TNF- $\alpha$ and IL-1 $\beta$ ) and inflammatory mediators such as NO.

\section{Anti-Toll-like receptor 4 antibody inhibited SFA-induced $N F-\kappa B$ activation and pro-inflammatory mediator production}

We next investigated whether PA-induced activation of NF-кB was regulated via TLR4. Fig. 8(a) shows that at $1 \mathrm{~h}$ of PA treatment, the p65 translocation of NF- $\mathrm{kB}$ was significantly increased. Incubating the cells with anti-TLR $4 \mathrm{Ab}(10 \mu \mathrm{g} / \mathrm{ml}$, a non-toxic concentration), however, prevented the PAinduced activation of $\mathrm{NF}-\kappa \mathrm{B}$, suggesting an involvement of TLR4 in the activation of the transcriptional factors. Moreover, treatment of BV-2 cells with anti-TLR4 Ab inhibited PAinduced production of pro-inflammatory mediators (Fig. 8(b)). 
(a)
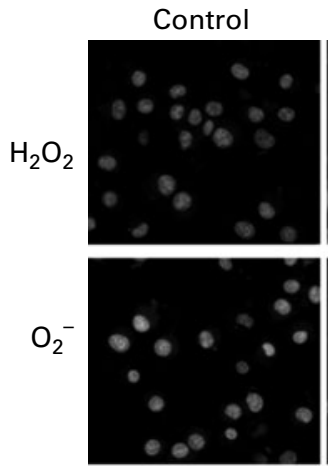

(b)

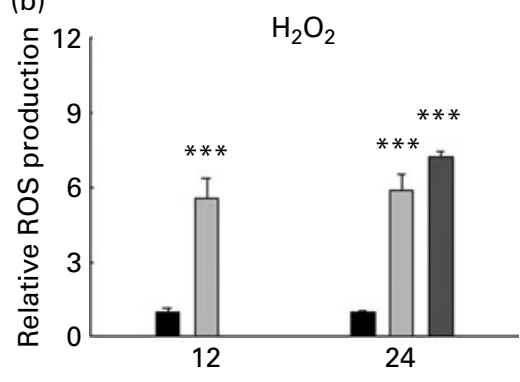

Incubation time (h)
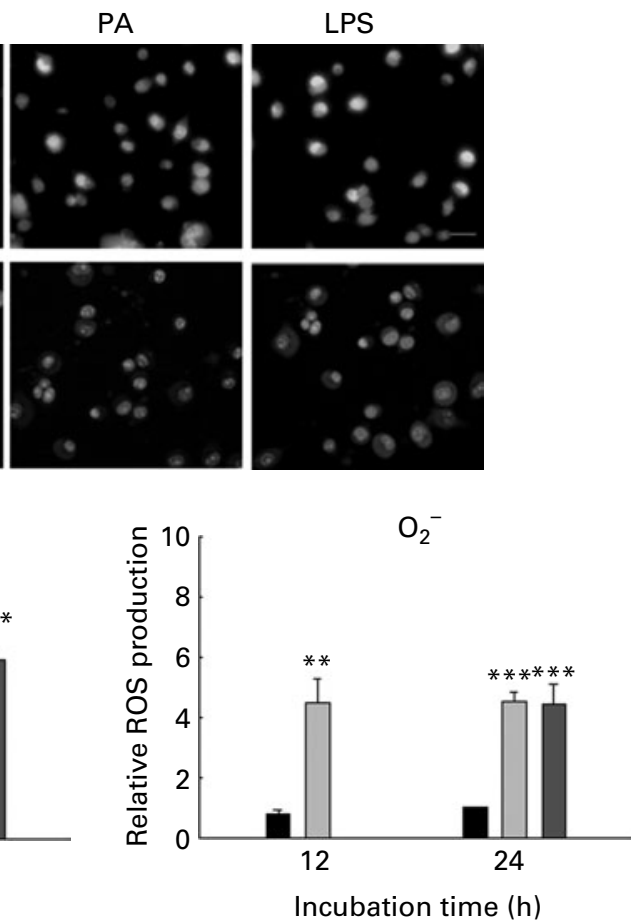

Fig. 4. SFA increase intracellular reactive oxygen species (ROS). (a) BV-2 cells were incubated in the absence or presence of palmitic acid (PA; $100 \mu \mathrm{M})$ for 12 and $24 \mathrm{~h}$, or lipopolysaccharide (LPS; $500 \mathrm{ng} / \mathrm{ml}$ ) for $24 \mathrm{~h}$. Following incubation and washing with PBS, the cells were treated with $10 \mu \mathrm{M}-2^{\prime}, 7^{\prime}$-dichlorodihydrofluorescein diacetate $\left(\mathrm{H}_{2} \mathrm{DCFDA}\right)$ or $2 \mu \mathrm{M}$-dihydroethidium (DHE) and counterstained with 4',6-diamidino-2-phenylindole (DAPI), and ROS were detected by using a fluorescence microscope. Scale bar $=20 \mu \mathrm{m}$. Images are representative of triplicate sets. (b) Quantification of the ROS was determined by fluorescence plate

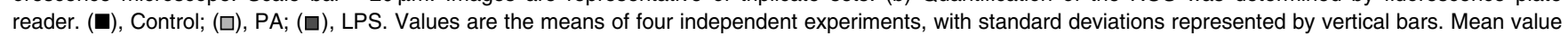
was significantly different from that of the control: ${ }^{\star \star} P<0.01,{ }^{\star \star *} P<0.001$.

\section{Discussion}

The present results have shown that SFA can induce microglial activation as manifested by its actions on BV-2 cells and primary microglial cells. We have shown that SFA treatment induced microglial activation, as shown by changes in cell morphology consistent with a reactive phenotype, and caused significantly higher production of ROS, NO, and proinflammatory cytokines including TNF- $\alpha$, IL- $1 \beta$ and IL- 6 in microglia, resulting in bystander neuronal death. Moreover, PA treatment induced a marked expression of IL-1 $\beta$ and iNOS comparable with that with LPS. Additionally, we have shown that PA treatment activated NF-кB. It is striking that inhibition of NF- $\mathrm{kB}$ activation, with its inhibitor PDTC resulted in inhibition of iNOS, TNF- $\alpha$, IL- $1 \beta$ and IL- 6 mRNA expression, and production of TNF- $\alpha$, IL- $1 \beta$ and NO except for IL-6. Another major finding was that in cells treated with antiTLR4 Ab, PA-induced NF- $\kappa \mathrm{B}$ activation and pro-inflammatory mediator production were repressed. These results suggest that SFA could activate microglia and stimulate the TLR4NF- $\kappa$ B pathway to trigger the production of pro-inflammatory mediators, which may contribute to neuronal death.

Microglia adapt to different CNS environments and exhibit diverse morphological types and functional specialisations ${ }^{(24)}$. Our findings have demonstrated that BV-2 cells and primary microglial cells exposed to SFA assumed an amoeboid morphology and increased CD11b expression, which are indicative of its activated state.
It has been reported that the pro-inflammatory cytokines TNF- $\alpha$, IL-1 $\beta$ and IL-6, which are important factors in the regulation of inflammatory processes, are overexpressed in the brain of $\mathrm{AD}$ patients ${ }^{(25-27)}$, indicating the possible involvement of these cytokines in the pathology of the disease. Indeed, the present results have shown that PA and SA increased TNF- $\alpha$, IL- $1 \beta$ and IL- 6 mRNA expression and cytokine secretion. Along with the pro-inflammatory cytokines, $\mathrm{NO}$ is an important contributor to neuronal damage in $\mathrm{AD}$ development ${ }^{(28)}$. Following PA stimulation, there was a marked increase in NO production by BV-2 cells. Moreover, iNOS expression was also enhanced after PA treatment for 6 and $24 \mathrm{~h}$. It is suggested that SFA treatment had induced iNOS up-regulation in microglia resulting in increased production of NO.

Like LPS, PA enhanced TNF- $\alpha$, IL- 6 and IL-1 $\beta$ production in microglia. However, it is remarkable that PA treatment had resulted in more vigorous IL- $1 \beta$ up-regulation. IL- $1 \beta$ is a critical inflammatory cytokine in $\mathrm{AD}$, and found in activated microglia localised to amyloid plaques ${ }^{(29)}$. IL-1 $\beta$ induces amyloid $\beta$ deposition through directly up-regulating expression and processing of $\beta$-amyloid precursor proteins ${ }^{(30,31)}$. It increases tau phosphorylation by mitogen-activated protein kinase $\mathrm{p} 38^{(32)}$. It activates astrocytes to overexpress S100 $\beta$, which stimulates neurite growth and increases Ca flux (a deadly event) in neurons ${ }^{(33)}$. Moreover, it also stimulates astrocytes to produce additional pro-inflammatory cytokines such as IL- $^{(34,35)}$. IL-1 $\beta$ has been reported to promote the 
(a)

PA-conditioned medium
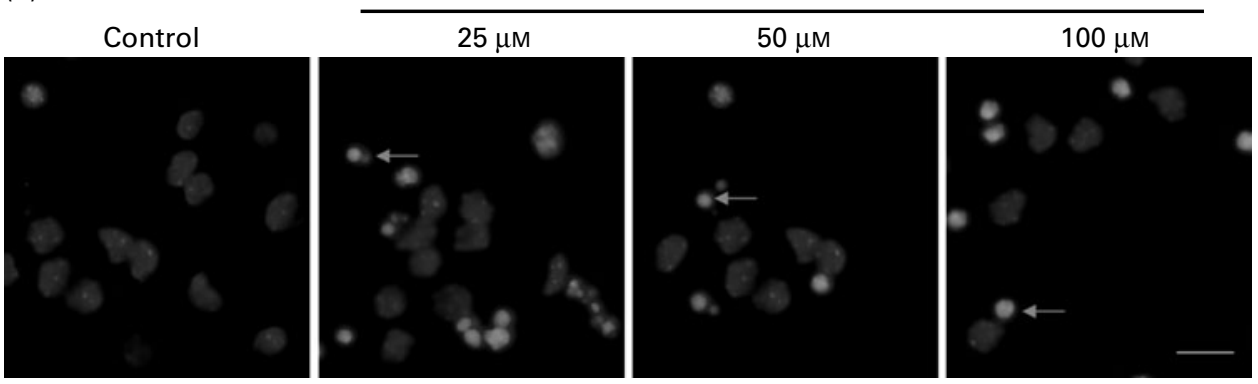

(b)

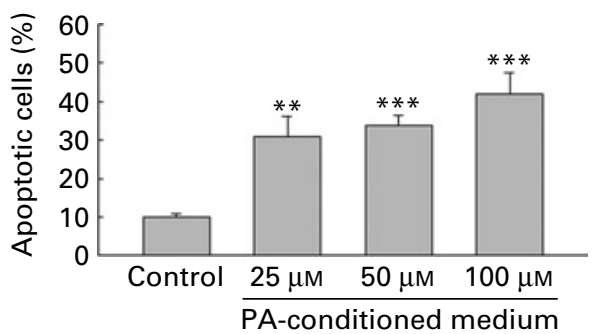

Fig. 5. Bystander neuronal death caused by SFA-treated microglia. (a) BV-2 cells were incubated in the absence or presence of palmitic acid (PA; $25-100 \mu M)$ for $12 \mathrm{~h}$. The medium was changed with fresh serum-free Dulbecco's modified Eagle's medium (DMEM) for $12 \mathrm{~h}$. The supernatant fractions were collected, filtered and stored at $-20^{\circ} \mathrm{C}$. Primary cortical neurons were treated with these culture supernatant fractions for $48 \mathrm{~h}$ and stained with Hoechst 33342 . $\leftarrow$, Representative apoptotic nuclei (scale bar $=10 \mu \mathrm{m}$ ). Images are representative of triplicate sets. (b) Apoptotic nuclei were quantified in ten random fields for each experimental condition. Values are the means of three independent experiments, with standard deviations represented by vertical bars. Mean value was significantly different from that of the control: ${ }^{\star *} P<0.01,{ }^{\star * *} P<0.001$.

activation activity of the enzyme acetylcholinesterase, thus down-regulating the cholinergic system ${ }^{(36)}$. Finally, IL-1 directly promotes microglial proliferation ${ }^{(37)}$ and increases microglial expression of IL- $1 \beta$ and IL- $6^{(38)}$. All these IL-1 $\beta$ regulated processes might result in neuronal stress or injury, which in turn further enhances microglial activation and
IL-1 $\beta$ overexpression. Thus IL-1 $\beta$ plays a pivotal role in the pathogenesis of $\mathrm{AD}$. In addition, IL- $1 \beta$ is known to be involved in the expression and activation of iNOS ${ }^{(39)}$. Interestingly, we have found that PA treatment enhanced a marked iNOS expression at a level comparable with that induced by LPS. It is suggested that PA directly activates microglia, and
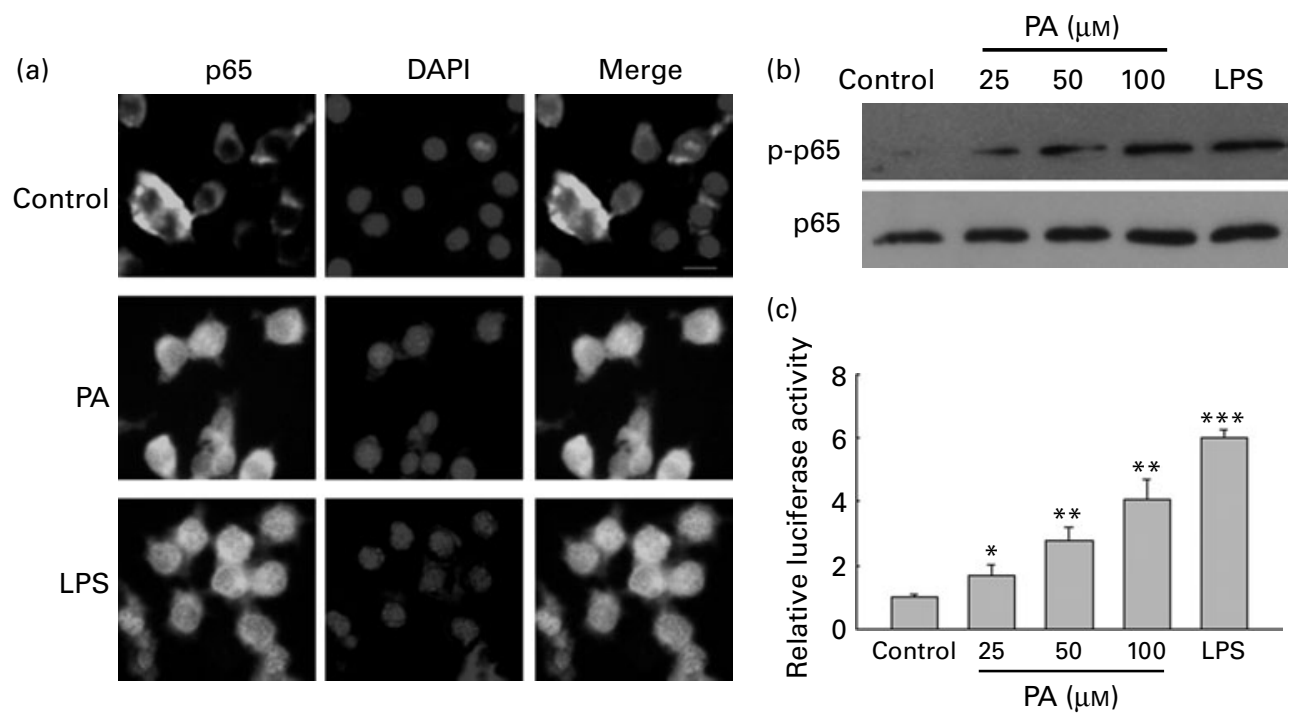

Fig. 6. SFA induce NF-кB activation. (a) BV-2 cells were incubated in the absence or presence of palmitic acid (PA; $100 \mu \mathrm{M})$ or lipopolysaccharide (LPS; $500 \mathrm{ng} / \mathrm{ml}$ ) for $1 \mathrm{~h}$ and stained for NF-kB p65 and counterstained with $4^{\prime}, 6$-diamidino-2-phenylindole (DAPI). Then images were captured by a fluorescence microscope. Scale bar $=20 \mu \mathrm{m}$. (b) BV-2 cells were incubated in the absence or presence of PA $(25-100 \mu \mathrm{M})$ or LPS (500 ng/ml) for $1 \mathrm{~h}$ and $30 \mu \mathrm{g}$ total protein were subjected to Western blot analysis. A phospho-specific antibody that recognises the phosphorylation of the serine 536 residue on the p65 ( $p$-p65) determined the

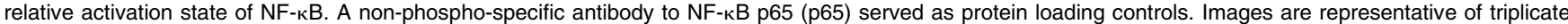
sets. (c) BV-2 cells were incubated in the absence or presence of PA (25-100 $\mu \mathrm{M}$ ) or LPS (500 ng/ml) for $24 \mathrm{~h}$. The effect of PA on NF-kB promoter activity was evaluated by luciferase assay as described in Materials and methods. Values are the means of three independent experiments, with standard deviations represented by vertical bars. Mean value was significantly different from that of the control: ${ }^{\star} P<0.05,{ }^{\star \star} P<0.01,{ }^{\star \star *} P<0.001$. 

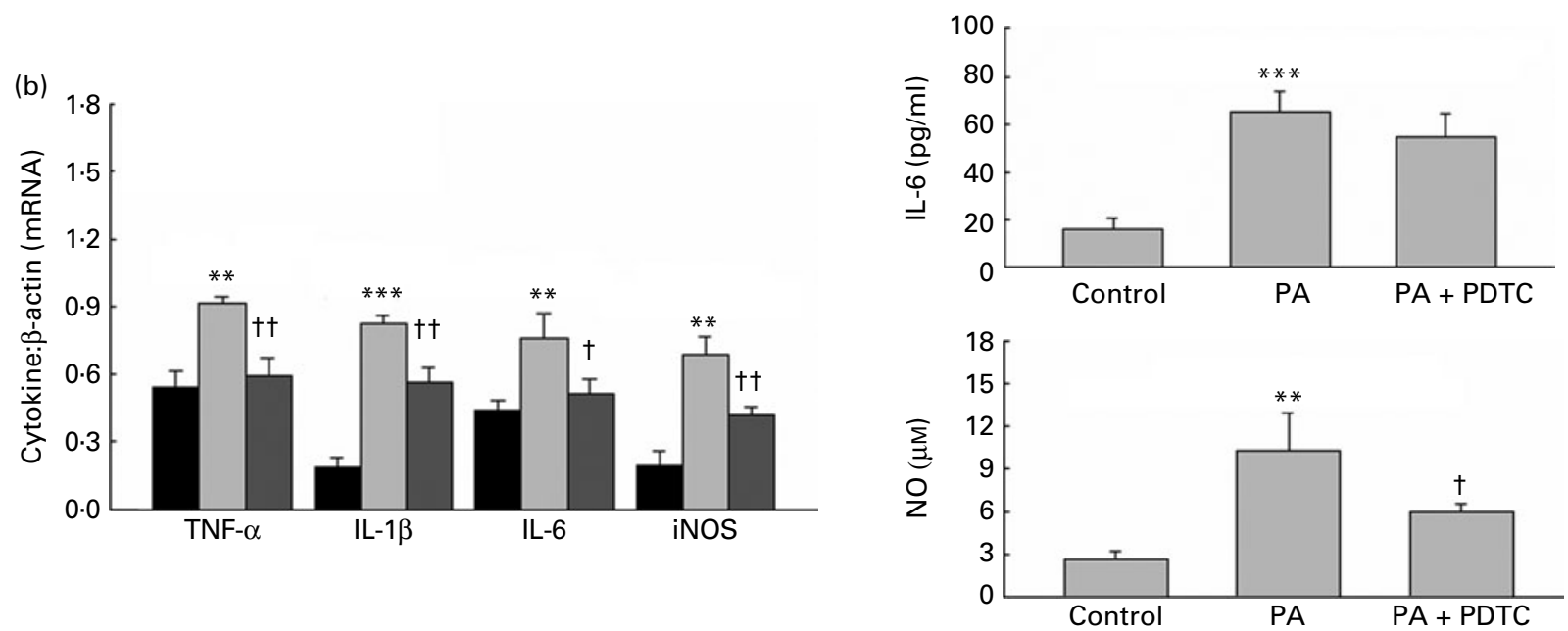

Fig. 7. Pyrrolidine dithiocarbamate (PDTC) inhibits SFA-induced cytokine and NO release. (a) BV-2 cells were incubated in the absence or presence of palmitic acid $(\mathrm{PA} ; 100 \mu \mathrm{M})$, alone or in combination with PDTC $(100 \mu \mathrm{M})$, for $4 \mathrm{~h}$. The relative expression levels of TNF- $\alpha$, IL-1 $\beta$, IL- 6 and inducible NO synthase (iNOS) genes were analysed by semi-quantitative RT-PCR. Each value was normalised to $\beta$-actin. (b) Quantification of mRNA levels of TNF- $\alpha$, IL-1 $\beta$, IL-6 and iNOS

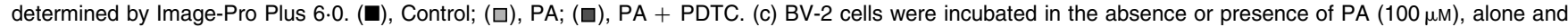
in combination with PDTC $(100 \mu \mathrm{M})$, for $24 \mathrm{~h}$. TNF- $\alpha$, IL-1 $\beta$, IL-6 and NO production was measured. Values are the means of four independent experiments, with standard deviations represented by vertical bars. Mean value was significantly different from that of the control: ${ }^{\star \star} P<0.01,{ }^{\star \star \star} P<0.001$. Mean value was significantly different from that of $\mathrm{PA}$ alone: $\dagger P<0.05$, $\dagger+P<0.01$.

increases IL-1 $\beta$ production, which may lead to enhanced iNOS expression. The above results indicate that IL-1 $\beta$ may play a key and detrimental role in regulating the SFA-induced inflammatory response.

Analysis of the regulation of inducible transcription factors has claimed a major role for the NF- $\mathrm{KB}$ system in the activation of microglial cells in neurodegenerative diseases. Activation of $\mathrm{NF}-\kappa \mathrm{B}$ has been linked to the up-regulation of potentially inflammation-related genes, including iNOS, cyclo-oxygenase2 , TNF- $\alpha$, IL-1 $\beta$ and IL- 6 . Previous studies have demonstrated that SFA can induce NF- $\mathrm{B}$ activation in macrophages ${ }^{(40)}$. The present results have shown that PA enhanced p65 nuclear translocation, phosphorylation and $\mathrm{NF}-\kappa \mathrm{B}$ promoter activity. Furthermore, PDTC, a potent NF- $\kappa \mathrm{B}$ inhibitor, suppressed PA-induced NO, TNF- $\alpha$ and IL- $1 \beta$ production in BV-2 cells, while PA-induced IL-6 production was not affected. It is therefore suggested that NO, TNF- $\alpha$ and IL-1 $\beta$ are downstream gene products of the NF- $\mathrm{BB}$ pathway induced by PA, whereas the effect of PA on IL-6 is independent of the NF-кB pathway. It is possible that other transcriptional factors may be involved in IL- 6 production, for example, activating protein- ${ }^{(41)}$, cAMP-induced transcription factors such as cAMP-responsive element binding protein and CCAAT-enhancer box binding protein ${ }^{(42,43)}$, or signal transducer and activator of transcription ${ }^{(44)}$. PA may be able to activate one of these transcriptional factors, increasing IL-6 production.

Several previous results have demonstrated that the stimulation of TLR4 by SFA can trigger transcription factor activation, leading to the production of pro-inflammatory mediators in monocytes and macrophages in vitro ${ }^{(45)}$. However, recent studies have called into question the ability of 
(a)

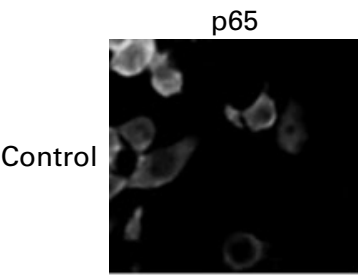

PA

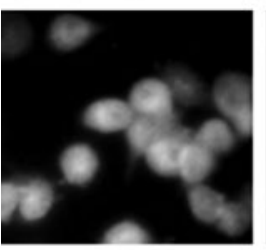

(b)

PA + anti-TLR4

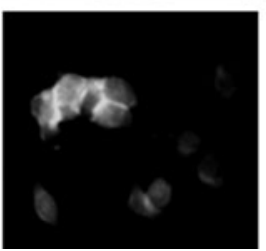

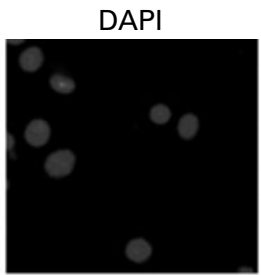
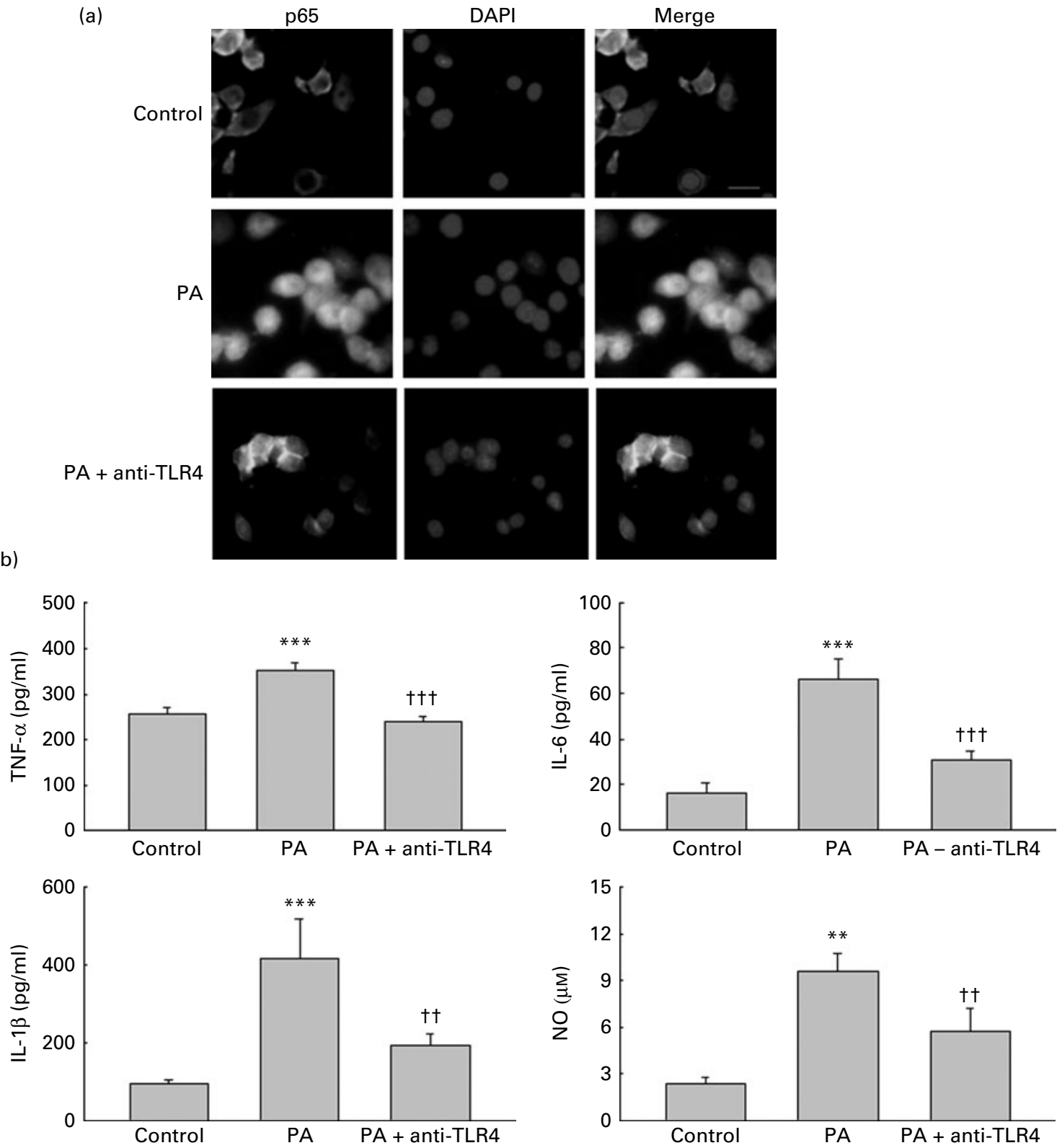

Fig. 8. Effects of antibody-mediated Toll-like receptor (TLR)-4 blockade on SFA-induced NF-кB activation and pro-inflammatory mediator production. (a) BV-2 cells were incubated in the absence or presence of PA $(100 \mu \mathrm{M})$, alone or in combination with anti-TLR4-neutralising antibody for $1 \mathrm{~h}$. The cells were stained for NF-кB p65 and counterstained with 4',6-diamidino-2-phenylindole (DAPI). Then images were captured in a fluorescence microscope. Scale bar $=20 \mu \mathrm{m}$. Images are representative of triplicate sets. (b) BV-2 cells were incubated in the absence or presence of PA $(100 \mu \mathrm{M})$, alone and in combination with anti-TLR4-neutralising antibody for $24 \mathrm{~h}$. TNF- $\alpha$, IL-1 $\beta$, IL- 6 and NO production was measured. Values are the means of four independent experiments, with standard deviations represented by vertical bars. Mean value was significantly different from that of the control: ${ }^{\star \star} P<0.01,{ }^{\star \star \star} P<0.001$. Mean value was significantly different from that of $\mathrm{PA}$ alone: $\dagger \dagger P<0.01$, ††† $P<0.001$.

TLR to directly bind SFA as a ligand and suggest that SFA might modulate TLR activity via lipid raft changes ${ }^{(46)}$ or that SFA may induce inflammation via TLR-independent mechanisms ${ }^{(47)}$. In the present study anti-TLR4 Ab reversed the PA-induced NF- $\mathrm{BB}$ p 65 translocation and pro-inflammatory mediator production. Thus, it is hypothesised that TLR 4 may mediate NF- $\kappa \mathrm{B}$ activation in PA-induced microglia activation. On the other hand, the mechanism by which PA can activate TLR 4 remains to be clarified. It is evident that the above-mentioned effects of SFA on BV-2 cells were not due to cytotoxicity, because no significant cell death was observed in the concentration ranges examined.

Against the above background, we then determined whether culture supernatant fractions derived from microglia treated with PA could actually affect neuronal survivability. Indeed, on addition of the supernatant fractions into primary neuronal culture, there was a significant reduction of neuronal viability. Thus, the combination of ROS, NO and pro-inflammatory cytokines seems to act in a synergistic way to cause bystander death to neurons. 
In conclusion, the present study has shown that SFA can cause activation of microglial cells, resulting in the generation of pro-inflammatory cytokines, NO and ROS, which could, in turn, induce neuronal dysfunctions. PA treatment markedly increases the expression of IL- $1 \beta$ and iNOS to a level comparable with that with LPS. PA induced the TLR4-mediated activation of NF- $\kappa$, which is responsible for TNF- $\alpha$, IL- $1 \beta$ and NO production. The possibility of PA activation of other pathways should be considered. This takes into consideration the fact that inhibition of NF- $\mathrm{B}$ B did not alter IL- 6 production. The present novel findings suggest the potential mechanisms in SFA-induced microglial activation and, to this end, nutrition rich in SFA may be linked to some inflammatory diseases of the CNS.

\section{Acknowledgements}

The present study was supported by funding from the National Basic Research Program of China (973 Program, no. 2007CB512001, 2011CB966201); National Natural Science Foundation of China (no. 30771142, 81071057); Natural Science Foundation of Shandong Province (no. Z2007C11, J200823, ZR2010HQ022).

Z. W. and D. L. contributed equally to the present study. The authors' contributions were: A. H. was involved in study design, data interpretation and manuscript editing; $Z$. W. and D. L. performed the majority of the laboratory work and contributed to the analysis of data and writing of the manuscript; F. W. and S. L. were responsible for the cell culture; S. Z. and E.-A. L. were involved in manuscript editing.

The authors have no conflict of interest to declare.

\section{References}

1. Eskelinen MH, Ngandu T, Helkala EL, et al. (2008) Fat intake at midlife and cognitive impairment later in life: a population-based CAIDE study. Int $J$ Geriatr Psychiatry 23, 741-747.

2. Morris MC, Evans DA, Bienias JL, et al. (2004) Dietary fat intake and 6-year cognitive change in an older biracial community population. Neurology 62, 1573-1579.

3. Solfrizzi V, D'Introno A, Colacicco AM, et al. (2005) Dietary fatty acids intake: possible role in cognitive decline and dementia. Exp Gerontol 40, 257-270.

4. Morris MC, Evans DA, Tangney CC, et al. (2006) Dietary copper and high saturated and trans fat intakes associated with cognitive decline. Arch Neurol 63, 1085-1088.

5. Greenwood CE \& Winocur G (1996) Cognitive impairment in rats fed high-fat diets: a specific effect of saturated fatty-acid intake. Behav Neurosci 110, 451-459.

6. Granholm AC, Bimonte-Nelson HA, Moore AB, et al. (2008) Effects of a saturated fat and high cholesterol diet on memory and hippocampal morphology in the middle-aged rat. J Alzheimers Dis 14, 133-145.

7. Dhopeshwarkar GA \& Mead JF (1973) Uptake and transport of fatty acids into the brain and the role of the blood-brain barrier system. Adv Lipid Res 11, 109-142.

8. Wang SW, Wang M, Grossman BM, et al. (1994) Effects of dietary fat on food intake and brain uptake and oxidation of fatty acids. Physiol Behav 56, 517-522.
9. Goux WJ, Rodriguez S \& Sparkman DR (1995) Analysis of the core components of Alzheimer paired helical filaments. A gas chromatography/mass spectrometry characterization of fatty acids, carbohydrates and long-chain bases. FEBS Lett 366, 81-85.

10. Roher AE, Weiss N, Kokjohn TA, et al. (2002) Increased A $\beta$ peptides and reduced cholesterol and myelin proteins characterize white matter degeneration in Alzheimer's disease. Biochemistry 41, 11080-11090.

11. Patil S \& Chan C (2005) Palmitic and stearic fatty acids induce Alzheimer-like hyperphosphorylation of tau in primary rat cortical neurons. Neurosci Lett 384, 288-293.

12. Patil S, Sheng L, Masserang A, et al. (2006) Palmitic acid-treated astrocytes induce BACE1 upregulation and accumulation of C-terminal fragment of APP in primary cortical neurons. Neurosci Lett 406, 55-59.

13. Patil S, Melrose J \& Chan C (2007) Involvement of astroglial ceramide in palmitic acid-induced Alzheimer-like changes in primary neurons. Eur J Neurosci 26, 2131-2141.

14. Wilson DM \& Binder LI (1997) Free fatty acids stimulate the polymerization of tau and amyloid $\beta$ peptides. In vitro evidence for a common effector of pathogenesis in Alzheimer's disease. Am J Pathol 150, 2181-2195.

15. Frank-Cannon TC, Alto LT, McAlpine FE, et al. (2009) Does neuroinflammation fan the flame in neurodegenerative diseases? Mol Neurodegener 4, 47

16. Block ML \& Hong JS (2007) Chronic microglial activation and progressive dopaminergic neurotoxicity. Biochem Soc Trans 35, 1127-1132.

17. Cao Q, Lu J, Kaur C, et al. (2008) Expression of Notch-1 receptor and its ligands Jagged-1 and Delta-1 in amoeboid microglia in postnatal rat brain and murine BV-2 cells. Glia 56, 1224-1237.

18. Lee JY, Sohn KH, Rhee SH, et al. (2001) Saturated fatty acids, but not unsaturated fatty acids, induce the expression of cyclooxygenase-2 mediated through Toll-like receptor 4. J Biol Chem 276, 16683-16689.

19. Fernandez-Lizarbe S, Pascual M \& Guerri C (2009) Critical role of TLR 4 response in the activation of microglia induced by ethanol. $J$ Immunol 183, 4733-4744.

20. Brahmachari S, Jana A \& Pahan K (2009) Sodium benzoate, a metabolite of cinnamon and a food additive, reduces microglial and astroglial inflammatory responses. J Immunol 183, 5917-5927.

21. Ghoshal A, Das S, Ghosh S, et al. (2007) Proinflammatory mediators released by activated microglia induces neuronal death in Japanese encephalitis. Glia 55, 483-496.

22. Pahl HL (1999) Activators and target genes of Rel/NF- $\mathrm{BB}$ transcription factors. Oncogene 18, 6853-6866.

23. Neumann M \& Naumann M (2007) Beyond IкBs: alternative regulation of NF-кB activity. FASEB J 21, 2642-2654.

24. Henn A, Lund S, Hedtjarn M, et al. (2009) The suitability of BV2 cells as alternative model system for primary microglia cultures or for animal experiments examining brain inflammation. ALTEX 26, 83-94.

25. Tobinick E (2009) Tumour necrosis factor modulation for treatment of Alzheimer's disease: rationale and current evidence. CNS Drugs 23, 713-725.

26. Di Bona D, Plaia A, Vasto S, et al. (2008) Association between the interleukin- $1 \beta$ polymorphisms and Alzheimer's disease: a systematic review and meta-analysis. Brain Res Rev 59, 155-163

27. Hull M, Berger M, Volk B, et al. (1996) Occurrence of interleukin- 6 in cortical plaques of Alzheimer's disease patients may precede transformation of diffuse into neuritic plaques. Ann N Y Acad Sci 777, 205-212. 
28. Wei T, Chen C, Hou J, et al. (2000) Nitric oxide induces oxidative stress and apoptosis in neuronal cells. Biochim Biophys Acta 1498, 72-79.

29. Sheng JG, Mrak RE \& Griffin WS (1995) Microglial interleukin-1 $\alpha$ expression in brain regions in Alzheimer's disease: correlation with neuritic plaque distribution. Neuropathol Appl Neurobiol 21, 290-301.

30. Forloni G, Demicheli F, Giorgi S, et al. (1992) Expression of amyloid precursor protein mRNAs in endothelial, neuronal and glial cells: modulation by interleukin-1. Brain Res Mol Brain Res 16, 128-134.

31. Goldgaber D, Harris HW, Hla T, et al. (1989) Interleukin 1 regulates synthesis of amyloid $\beta$-protein precursor mRNA in human endothelial cells. Proc Natl Acad Sci U S A 86, $7606-7610$.

32. Li Y, Liu L, Barger SW, et al. (2003) Interleukin-1 mediates pathological effects of microglia on tau phosphorylation and on synaptophysin synthesis in cortical neurons through a p38-MAPK pathway. $J$ Neurosci 23, 1605-1611.

33. Sheng JG, Ito K, Skinner RD, et al. (1996) In vivo and in vitro evidence supporting a role for the inflammatory cytokine interleukin-1 as a driving force in Alzheimer pathogenesis. Neurobiol Aging 17, 761-766.

34. Blom MA, van Twillert MG, de Vries SC, et al. (1997) NSAIDS inhibit the IL- $1 \beta$-induced IL- 6 release from human postmortem astrocytes: the involvement of prostaglandin E2. Brain Res 777, 210-218.

35. Griffin WS, Sheng JG, Royston MC, et al. (1998) Glial-neuronal interactions in Alzheimer's disease: the potential role of a 'cytokine cycle' in disease progression. Brain Pathol 8, 65-72.

36. Li Y, Liu L, Kang J, et al. (2000) Neuronal-glial interactions mediated by interleukin-1 enhance neuronal acetylcholinesterase activity and mRNA expression. J Neurosci 20, 149-155.

37. Ganter S, Northoff H, Mannel D, et al. (1992) Growth control of cultured microglia. J Neurosci Res 33, 218-230.
38. Sebire G, Emilie D, Wallon C, et al. (1993) In vitro production of IL-6, IL-1 $\beta$, and tumor necrosis factor $\alpha$ by human embryonic microglial and neural cells. J Immunol 150, 1517-1523.

39. Akama KT \& Van Eldik LJ (2000) $\beta$-Amyloid stimulation of inducible nitric-oxide synthase in astrocytes is interleukin$1 \beta$ - and tumor necrosis factor- $\alpha$ (TNF $\alpha$ )-dependent, and involves a TNF $\alpha$ receptor-associated factor- and NFKBinducing kinase-dependent signaling mechanism. I Biol Chem 275, 7918-7924.

40. Shi H, Kokoeva MV, Inouye K, et al. (2006) TLR4 links innate immunity and fatty acid-induced insulin resistance. $J$ Clin Invest 116, 3015-3025.

41. Rohrbach S, Engelhardt S, Lohse MJ, et al. (2007) Activation of AP-1 contributes to the $\beta$-adrenoceptor-mediated myocardial induction of interleukin-6. Mol Med 13, 605-614.

42. Spooren A, Kooijman R, Lintermans B, et al. (2010) Cooperation of $\mathrm{NF \kappa B}$ and CREB to induce synergistic IL-6 expression in astrocytes. Cell Signal 22, 871-881.

43. Tchivileva IE, Tan KS, Gambarian M, et al. (2009) Signaling pathways mediating $\beta 3$-adrenergic receptor-induced production of interleukin-6 in adipocytes. Mol Immunol 46, 2256-2266.

44. Lee C, Lim HK, Sakong J, et al. (2006) Janus kinase-signal transducer and activator of transcription mediates phosphatidic acid-induced interleukin (IL)- $1 \beta$ and IL-6 production. Mol Pharmacol 69, 1041-1047.

45. Laine PS, Schwartz EA, Wang Y, et al. (2007) Palmitic acid induces IP-10 expression in human macrophages via NF-кB activation. Biochem Biophys Res Commun 358, 150-155.

46. Wong SW, Kwon MJ, Choi AM, et al. (2009) Fatty acids modulate Toll-like receptor 4 activation through regulation of receptor dimerization and recruitment into lipid rafts in a reactive oxygen species-dependent manner. $\mathrm{J} \mathrm{Biol} \mathrm{Chem}$ 284, 27384-27392.

47. Erridge C \& Samani NJ (2009) Saturated fatty acids do not directly stimulate Toll-like receptor signaling. Arterioscler Thromb Vasc Biol 29, 1944-1949. 